\title{
Enuresis and Encopresis: Remarks about a Possible Sharing
}

\author{
Bolla G., Sercia F., Longo R. \\ Department of Paediatric Urology, Public Hospital Dolo, Venice, Italy
}

Email address:

giorgio.bolla@libero.it (Bolla G.)

To cite this article:

Bolla G., Sercia F., Longo R.. Enuresis and Encopresis: Remarks about a Possible Sharing. Clinical Medicine Research. Vol. 4, No. 5, 2014, pp. 160-162. doi: 10.11648/j.cmr.20150405.17

\begin{abstract}
The clinical experience tends towards a possible sharing between enuresis and encopresis in pediatric age. This pattern goes back again to a maturative delay in the neurofunctional competence. The differentiation of therapies for nocturnal enuresis and for encopresis responds to the peculiarities of children and their families.
\end{abstract}

Keywords: Enuresis, Encopresis, Maturative Delay

\section{Background - Methodology}

Nocturnal enuresis is urinary incontinence for nighttime, beyond six years: primary enuresis concerns the children who have never been successfully trained to control urination, while secondary enuresis goes back again to children who have been successfully trained but revert to wetting in a response to some sort of stressful situation. This last condition is less frequent than primary enuresis. The classical definition of mono-symptomatic nocturnal enuresis assumes a clinical situation without daytime incontinence. Nocturnal enuresis results when the bladder is able to fill to its functional capacity and contracts reflexively during sleep. While nocturnal enuresis is normal in infants, a series of maturational processes, hormonal, neural and structural, results in nocturnal urinary continence by age 5 years in most children. Maturational delay or pathological alteration in one or more of these processes can results in persistent primary enuresis or secondary onset of nocturnal enuresis, whit a possible presence of sleep troubles [1]. However, the tendency to spontaneous resolution of enuresis is equal to $15 \%$ per annum [2]. But it's at the present time accepted that the main principle of enuresis is a sleep trouble: in particular an anomaly of the secretory rhythm of antidiuretic hormone $(\mathrm{ADH})$ is supposed $[3,4]$. The treatment of enuresis is identifiable by some parallel courses, at times conjoint [5]. The acoustic alarm requests a good compliance of the family. The employment of the drug Desmopressin, in particular for the events in community of the child, takes on a signification in view of the hypothesis on the reduced nocturnal secretion of ADH. Finally, the employment of anticholinergic drugs is reserved to the situations with an important detrusor instability, instrumentally verified by an urodynamic study, causing some failures with other treatments and some events of diurnal enuresis [6,7]. The pharmacologic treatment, wanting in unfavourable effects, takes significance when there is need to resolve the problem of nocturnal enuresis rapidly - for instance in case of community journeys .

Encopresis is clinically defined by the rectal soiling or, alternatively, by the unintentional loss of fecal matter, prevalently in liquid state [8]. The prevalence of encopresis in four-years-olds is between one and three percent, more common in males than females; the clinical appearance is classificable by two different categories. The first situation is peculiar to the constipation: the fecal packing causes a way of sliding round the fecal mass from the liquid portion without a control as regards the child. This condition is named an overflow incontinence. On the contrary the second situation binds itself to the existence of anatomic and functional anomalies at expense of the sphincterial apparatus or to the circumstances of a psychodynamic disorder in the child. The treatment is according to the genesis: in the presence of constipation it is addressed to the resolution of it, whereas in the presence of anatomical anomalies (as the consequences of anorectal malformations or tethered cord [9] ) the therapeutic approach envisages the sphincterial functionality; in that case the diagnostic settlement necessitates a rectal manometry and a radiogram of sacrum. 
Moreover it must be borne in mind that a psychotherapy comes in handy for the sake of the reshuffling the emotionality into the child and his own family [10].

\section{Conclusion}

The Authors checked a concomitance of encopresis and enuresis for 4-5 percent of the children with enuresis five/eight-years-olds: this appraisal is clinical alone. Up to today there aren't aetiologic and pathogenic studies bearing out this attemptable datum.

\section{Iconography}

The Flow-Chart 1 - Enuresis - and the Flow-Chart 2 Encopresis - show their respective ways for the diagnosis and the treatment.
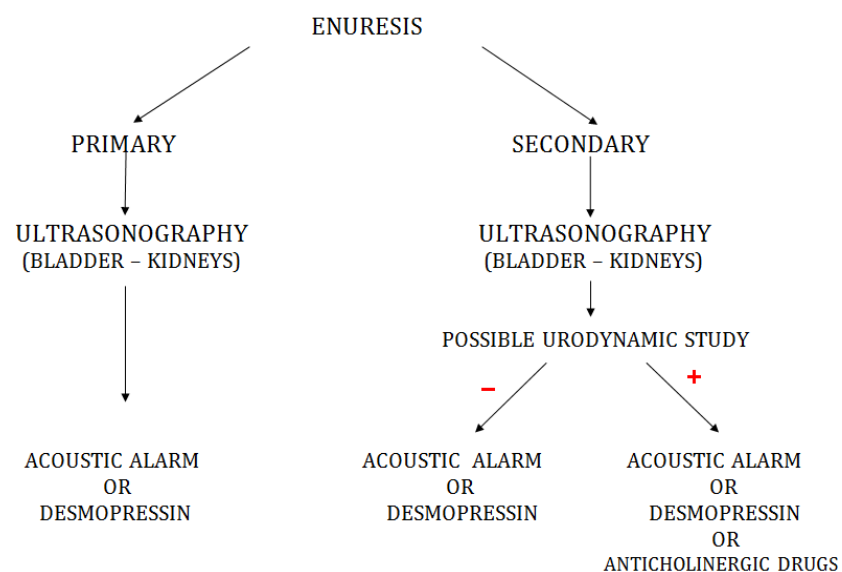

Fig. 1. The clinical pattern of Enuresis

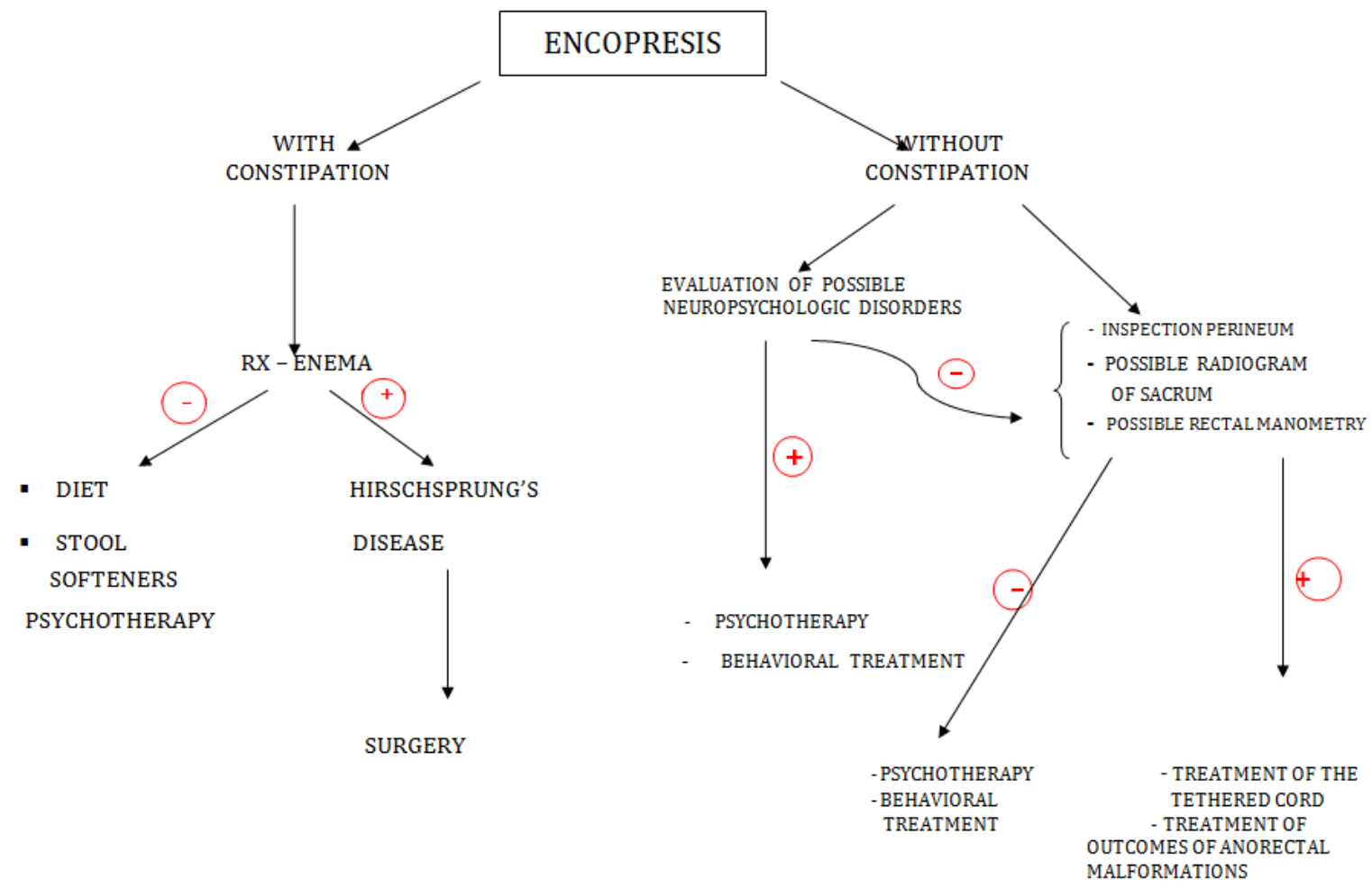

Fig. 2. The clinical pattern of Encopresis.

\section{References}

[1] Chandra M., Saharia R., Hill V., et al. Prevalence of diurnal voiding symptoms and difficult arousal from sleep in children with nocturnal enuresis (2004). J. Urol. 172:311-316.

[2] Hjalmas K., Arnold T., Bower W., et al. Nocturnal enuresis: an international evidence based management strategy (2004). J. Urol. 171:2545-2561.

[3] Dehoorne J.L.C., Vande Walle C., Vansintjan P., et al. Characteristics of a tertiary center enuresis population, with special emphasis on the relation among nocturnal diuresis, functional bladder capacity and desmopressin response (2007). J. Urol. 177:1130-1137.
[4] Kamperis K., Hansen M.N., Hagstroem M., et al. The circadian rhythm of urine production, and urinary vasopressin and prostaglandin E2 excretion in healthy children (2004) . J. Urol. 171:2571-2575.

[5] Van Kampen M., Bogaert G., Akinwuntan E.A., et al. Longterm efficacy and predictive factors of full spectrum therapy for nocturnal enuresis (2004). J. Urol. 171:2599-2602.

[6] Bolla G., Sartore G. Children with nocturnal enuresis: why several treatments ? (in Italian - 2010). Med. Surg. Ped. 179:226-228.

[7] Bolla G., Sartore G. Different therapeutical attitudes against enuresis: the prosecution of a clinical experience (2014). Am. J. Clin. Med. Res. Vol. 2, n 2:51-52. 
[8] Martelli H., Devroede G., Arhan P., et al. Mechanisms of idiopathic constipation: Outlet obstruction (1978). Gastroenterology 75:623-631.

[9] Peña A., Guardino K., Tovilla J.M., et al. Bowel management for fecal incontinence in patients with anorectal malformations (1998). J. Pediatr. Surg. 33:133-137.
[10] Friman P.C., Hofstadter K.L., Jones K.M. A biobehavioral approach to the treatment of functional encopresis in children (2006). JEIBI 3 (3):263-272. 